Revista Brasileira de Cartografia

ISSN 1808-0936 | https://doi.org/10.14393/revbrascartogr

Sociedade Brasileira de Cartografia, Geodésia, Fotogrametria e Sensoriamento Remoto

\title{
Sistemas Geodésicos de Referência: Rumo ao GGRS/GGRF
}

\section{Geodetic Reference Systems: Towards GGRS/GGRF}

\author{
Regiane Dalazoana ${ }^{1}$ e Sílvio Rogério Correia de Freitas ${ }^{2}$
}

1 Universidade Federal do Paraná, Curso de Pós-Graduação em Ciências Geodésicas, Curitiba, Brasil. regiane@ufpr.br ORCID: https://orcid.org/0000-0001-5468-0679

2 Universidade Federal do Paraná, Curso de Pós-Graduação em Ciências Geodésicas, Curitiba, Brasil. sfreitas@ufpr.br ORCID: https://orcid.org/0000-0003-0830-6541

Resumo: O estabelecimento de Sistemas Geodésicos de Referência globais integrando características geométricas e físicas é um dos desafios atuais da Geodésia, principalmente devido às demandas de diversas áreas do conhecimento de que as informações relacionadas aos Sistemas de Observação da Terra (EOS - Earth Observation Systems), sejam integradas em Redes Geodésicas de Referência (RGRs) com uma acurácia de $10^{-9}$ ou melhor. O surgimento das técnicas de posicionamento espacial trouxe melhora significativa na qualidade posicional e possibilitou a substituição das RGRs clássicas por redes modernas com características globais. Hoje, a questão das coordenadas de caráter geométrico, está bem resolvida com o ITRS/ITRF (International Terrestrial Reference System/International Terrestrial Reference Frame). Todavia, aspectos associados a diversos processos físicos, tais como os reflexos das redistribuições de massa, não são atendidos por referenciais puramente geométricos. A aprovação da resolução para o GGRS/GGRF (Global Geodetic Reference System/Global Geodetic Reference Frame) surge com a visão da integração entre o referencial terrestre, o celeste, um referencial com características físicas para as altitudes e a nova rede global de gravidade absoluta. Esforços têm sido feitos para definição e realização deste referencial global para as altitudes. É uma tarefa complexa em vista das características clássicas dos referenciais verticais, heterogeneidade em termos de qualidade e distribuição espacial de dados necessários, principalmente os relacionados ao campo de gravidade da Terra. Apresentam-se como grandes desafios para o futuro a necessidade de estabelecimento de procedimentos padrão para a integração ao referencial altimétrico global e a precisão necessária para o estabelecimento dos EOS.

Palavras-chave: Sistema Geodésico de Referência. Rede Geodésica de Referência. Altitudes Físicas. SIRGAS.

\begin{abstract}
One of the main challenges in Geodesy is the definition and realization of global Geodetic Reference Systems with geometric and physical characteristics. This is necessary to fulfill the demands of different knowledge areas where the observations related to Earth Observation Systems (EOS) must be integrated into reference frames with an accuracy of $10^{-9}$ or better. The development of satellite positioning systems has brought significant improvements in positional accuracy and made possible the replacement of local reference frames by global reference frames. Today, the geometric coordinates are well resolved with ITRS/ITRF (International Terrestrial Reference System/International Terrestrial Reference Frame). However, physical processes, like that related to mass distribution, are not attended by pure geometric reference systems. The resolution for the GGRS/GGRF (Global Geodetic Reference System/Global Geodetic Reference Frame) was approved with the aim to integrate the terrestrial reference system, the inertial reference system, a global reference system with physical meaning for the heights and the new global absolute gravity network. Efforts are been made to define and realize this height reference system. It is a complex task due to the classical characteristics of existing vertical reference systems, heterogeneity in terms of data accuracy and spatial distribution, especially those related to the Earth's gravity field. The need to establish standard procedures for the integration with a global height reference system and the precision needed for the establishment of the EOS are the big challenges for the future.
\end{abstract}

Keywords: Geodetic Reference System. Geodetic Reference Frame. Physical Heights. SIRGAS. 


\section{INTRODUÇÃO}

A definição, a realização e a manutenção de Sistemas Geodésicos de Referência (SGRs) foram, dentro de um contexto histórico, e têm sido, atualmente, parte das grandes atribuições da Geodésia nos contextos científicos e tecnológicos. Nesse sentido as aplicações práticas da Geodésia que estavam voltadas, principalmente, para a definição de limites, provisão de infraestrutura de dados para a Cartografia, Cadastro, Engenharia, entre inúmeras outras, se expandiram sobremaneira. Atualmente a Geodésia fornece o conhecimento necessário para o estabelecimento de Sistemas de Observação da Terra (EOS - Earth Observation Systems) que permitem analisar os fenômenos e efeitos relacionados aos processos físicos da Terra, fornecendo a infraestrutura necessária em termos de referenciais, bases de dados e produtos para entender as mudanças pelas quais o planeta vem passando e que impactam a sociedade como um todo (PLAG et al., 2009). Com esta visão, a IAG estabeleceu em julho de 2003, durante a XXIII International Union of Geodesy and Geophysics (IUGG) General Assembly, em Sapporo, Japão, o Global Geodetic Observing System (GGOS). O GGOS opera com as Comissões e Serviços componentes da IAG para prover a infraestrutura geodésica necessária para monitorar o Sistema Terra e para as pesquisas de mudanças globais. Dentro das perspectivas atuais, ele visa propiciar uma melhor compreensão da dinâmica do Sistema Terra quantificando as mudanças planetárias no espaço e no tempo (GGOS, 2020). Com o desenvolvimento do GGOS ao longo do tempo foram estabelecidas quatro áreas centrais de atuação (GGOS Focus Areas): 1. Sistema de Altitudes Físicas Unificado; 2. Catástrofes Naturais; 3. Mudanças no Nível do Mar, Variabilidade e Previsão Climática; 4. Pesquisa Geodésica de Clima Espacial.

A integração de referenciais com características geométricas e físicas é um dos grandes desafios que a Geodésia vem enfrentando nos últimos anos. Esse desafio vem da necessidade de que as observações relacionadas a Figura da Terra (geometria e cinemática), Campo da Gravidade (distribuição e redistribuição de massas) e Rotação da Terra (vínculo com o "espaço inercial"), conhecidos como os "três pilares da Geodésia" e suas atividades, sejam integradas a estruturas de referência com uma acurácia de $10^{-9}$ ou melhor.

Especificamente sobre os SGRs, do ponto de vista clássico tem-se como principais aspectos ou características: referenciais locais; de orientação topocêntrica; definidos apenas por parâmetros geométricos; separação entre a componente horizontal (latitude e longitude) e a componente vertical (altitude); a não consideração do aspecto temporal ao qual as coordenadas estão relacionadas; muitas vezes o desconhecimento das precisões associadas às coordenadas; a necessidade da realização a partir de um ponto origem (no Brasil denominado de Datum) e a materialização feita por técnicas convencionais de levantamentos geodésicos tais como a triangulação, poligonação e o nivelamento geométrico. Com o passar do tempo, e com o avanço tecnológico, surgiram novas metodologias, novos equipamentos, computadores cada vez mais potentes, novas modelagens matemáticas, resultando em observações cada vez mais precisas e necessidade de um tratamento mais refinado dos dados. Por exemplo, técnicas modernas de posicionamento espacial, como o VLBI (Very Long Baseline Interferometry), GPS (Global Positioning System) e o SLR (Satellite Laser Ranging), trouxeram uma melhora significativa na qualidade posicional e a possibilidade de substituir os referenciais clássicos por referenciais modernos com características globais, geocêntricos, tridimensionais (latitude, longitude e altitude elipsoidal), com informação acerca da qualidade e variação temporal das coordenadas. Estes novos referenciais envolvem, tanto em suas definições como em suas realizações, parâmetros geométricos e físicos.

Hoje, a questão das coordenadas geodésicas tridimensionais está bem resolvida com o ITRS/ITRF (International Terrestrial Reference System/International Terrestrial Reference Frame). Estas coordenadas geodésicas são usualmente expressas na forma cartesiana $(X, Y, Z)$ ou na forma elipsóidica como latitude $(\varphi)$, longitude $(\lambda)$ e altitude $(h)$. Como as altitudes ortométricas, normais, dinâmicas, entre outras com natureza física, ou as de natureza mista como a normal-ortométrica, são também coordenadas geodésicas, adota-se a expressão de altitude elipsoidal para $(h)$, o que também é consagrado na literatura internacional como ellipsoidal height (ver por exemplo HOFMANN-WELLENHOF; MORITZ, 2005, p. 72, 81, ...).

A definição do ITRS depende de constantes geodésicas fundamentais que envolvem a figura da Terra (dimensões), o campo da gravidade (fator dinâmico de forma e constante gravitacional geocêntrica) e rotação da Terra (velocidade angular) que serão discutidas na próxima seção. A realização ITRF depende da geometria 
e orientação no espaço de um poliedro global de estações ITRF, em dado instante de tempo, com o vínculo destas ao geocentro. Este geocentro é realizado, com base no geopotencial (ou potencial da gravidade), pois vincula-se à fixação de coeficientes harmônicos do campo da gravidade $\left(C_{10}, C_{11}\right.$ e $\left.S_{11}\right)$ todos como iguais a zero. Estes coeficientes estão associados com as coordenadas do centro de massa estimado para a época de referência, que é a origem usual do SGR global (LAMBECK, 1988, p.13). Um aspecto notável é o de que as variações temporais da latitude e longitude no ITRS são aspectos bem dominados e estabelecidos em modelos globais e regionais de velocidades, enquanto as variações nas altitudes são tópicos de vanguarda nas pesquisas em Geodésia. Nesse aspecto, destacam-se algumas pesquisas globais com participações brasileiras de Montecino et al. (2017), Ferreira et al. (2019) e Brassarote (2020).

O desenvolvimento dos EOS principalmente no que se refere aos aspectos de monitoramento e interpretação consistente de processos-chave da dinâmica planetária requerem estruturas de referência que integrem o espaço geométrico com o espaço físico associado com o geopotencial (ou potencial do campo da gravidade da Terra). Assim é que a Assembleia Geral das Nações Unidas estabeleceu, em resolução, um referencial geodésico para o desenvolvimento sustentável em 26 de fevereiro de 2015, adotando a abordagem estruturada da Geodésia, conforme pressupostos da IAG/GGOS, com suas Comissões e Serviços. Foi assim preconizado o GGRS/GGRF (Global Geodetic Reference System/Global Geodetic Reference Frame). Este surgiu com a visão da integração entre um SGR terrestre de características geométricas devidamente orientado em relação a um referencial celeste de característica fundamental e um referencial global para as altitudes com características físicas. Este último suposto a ser realizado no espaço do geopotencial, ou seja, a realização deste referencial global para as altitudes se dará com base na determinação do valor do geopotencial, em pontos sobre a superfície física da Terra, através da modelagem do potencial perturbador por meio de solução do Problema do Valor de Contorno da Geodésia (PVCG). Estes pressupostos foram vinculados a uma exigência de inserção de uma nova rede global de gravidade absoluta em substituição à IGSN71 (International Gravity Standardization Net 1971), visto que esta não atende mais aos propósitos mais atuais da Geodésia. Estas ideias foram consolidadas pela IAG em julho de 2015 de acordo com as resoluções: No. 1 que estabeleceu o IHRS (International Height Reference System) prevendo sua futura realização IHRF (International Height Reference Frame) baseada em números geopotenciais e No. 2 que estabeleceu a GAGN (Global Absolute Gravity Network). Em abril de 2016 a IAG manifestou um posicionamento formal a respeito do GGRS/GGRF com uma descrição pormenorizada da sua fundamentação e realização (IAG, 2016). Estes aspectos serão expostos na sequência deste trabalho.

Grandes esforços têm sido feitos para o estabelecimento de procedimentos de normatização do IHRS e no estabelecimento de road-maps para sua realização (IHRF) bem como da GAGN. Na América do Sul estes esforços concentram-se em atividades relacionadas ao Grupo de Trabalho III (GT-III) do Projeto SIRGAS. A complexidade da tarefa se dá principalmente em vista das características clássicas de definição e realização dos referenciais verticais, heterogeneidade em termos de qualidade e distribuição espacial de dados necessários, principalmente dos dados relacionados ao campo de gravidade da Terra. Apresentam-se como grandes desafios para o futuro a necessidade de estabelecimento de procedimentos padrão para a integração ao referencial altimétrico global e a precisão necessária para o estabelecimento dos EOS.

Nesse sentido, este trabalho busca trazer uma visão geral da evolução dos SGRs tanto no aspecto de definição quanto no de realização, buscando evidenciar a necessidade da introdução de aspectos físicos; abordar os aspectos mais atuais relacionados com o estabelecimento de um referencial unificado e com características físicas para as altitudes, e apresentar os desafios a serem enfrentados visando o estabelecimento dos EOS.

\section{SISTEMAS E REDES DE REFERÊNCIA CELESTES E TERRESTRES FUNDAMENTAIS}

A definição de um SGR, em uma visão mais conservadora, para o posicionamento geométrico tridimensional na superfície física da Terra, envolve o estabelecimento de um conjunto de parâmetros e convenções associadas a uma superfície de referência elipsoidal que é devidamente posicionada e orientada em relação à Terra. Constitui-se assim um referencial adequado para a atribuição de coordenadas a pontos 
sobre a superfície física da Terra. Modernamente a superfície de referência é estabelecida por um conjunto de parâmetros geométricos e físicos: constante gravitacional geocêntrica $(G M)$, semieixo maior $(a)$, fator dinâmico de forma $\left(J_{2}\right)$ e velocidade angular de rotação $(\omega)$. A definição do referencial explicita ainda sua origem, escala e época de referência (TORGE; MÜLLER, 2012).

Em uma visão atual, a realização ou materialização de um SGR é dada por um conjunto de pontos, implantados na superfície física da Terra, cujas coordenadas são determinadas tendo por base o referencial definido anteriormente. Esse conjunto de pontos constitui as chamadas redes geodésicas de referência que podem ter caráter global (e.g. ITRF2014), regional (e.g. SIRGAS - CON), nacional (e.g. SIRGAS2000) e ainda outras densificações tais como redes estaduais e municipais. Todas estas redes são usualmente estabelecidas de forma hierárquica como densificações da rede global mais fundamental. Isto ocorre graças às potencialidades do uso do GNSS (Global Navigation Satellite System) no estabelecimento dessas redes.

No entanto outros sistemas e outras redes geodésicas de referência coexistem com as mais atuais, como por exemplo redes estabelecidas por técnicas clássicas de levantamentos geodésicos. Assim é que as redes geodésicas são didaticamente divididas em: verticais ou altimétricas, onde a coordenada de interesse é a altitude, derivadas de nivelamento geométrico (para as quais deve-se buscar significado físico); horizontais clássicas, onde o interesse voltava-se para a determinação das coordenadas latitude e longitude, estas usualmente, e de forma errônea, eram muitas vezes denominadas de "planimétricas" (recorda-se que a superfície de referência para o estabelecimento destas coordenadas é o elipsoide, ou seja, uma superfície curva); e as tridimensionais atuais. A divisão referida, leva em conta o fato da coordenada possuir característica física ou puramente geométrica e ainda diferentes observações e técnicas de levantamentos de campo são utilizadas na implantação de cada tipo de rede. A Geodésia também se ocupa do estabelecimento de redes gravimétricas fundamentais e suas densificações (TORGE; MÜLLER, 2012).

Os sistemas de referência também são necessários para descrever a posição e o movimento de objetos no espaço, tais como satélites artificiais, quasares (quasi stellar radio sources) e até outros planetas. O vínculo entre os referenciais dito terrestres e os celestes é imprescindível dadas as bases e ferramentas da Geodésia moderna que se apoiam em grande parte nos métodos espaciais de observação.

\subsection{Aspectos clássicos da definição e realização de um Sistema Geodésico de Referência}

Nos SGRs clássicos a definição do elipsoide de referência era feita apenas por parâmetros geométricos, usualmente semieixo maior (a) e achatamento $(f)$ definido pela Eq. (1) (VANÍČEK; KRAKIWSKY, 1986):

$$
f=\frac{a-b}{a}
$$

com $b$ sendo o semieixo menor do elipsoide de revolução. A superfície de referência elipsoidal pode ainda ser definida pelo semieixo maior $(a)$ e semieixo menor $(b)$ ou ainda pelo semieixo maior $(a)$ e a excentricidade (e). A pesquisa por um elipsoide que melhor se ajustasse a Terra envolveu os cientistas desde o início do século XIX na busca por parâmetros cada vez mais refinados (SMITH, 1996).

O posicionamento e orientação do elipsoide de referência eram feitos de tal forma que se ajustasse a uma determinada região, país ou grupo de países. Nesse caso o elipsoide não é geocêntrico, ou seja, o centro do modelo não coincide com o centro de massa da Terra. Para posicionar e orientar o elipsoide de referência eram necessários seis parâmetros topocêntricos: as coordenadas geodésicas $(\varphi$ e $\lambda)$ de um ponto origem (denominado Datum); uma orientação inicial, dada por um azimute inicial; a distância ao longo da normal desde o elipsoide de referência até o geoide (altitude geoidal $N$ ), e as componentes do desvio da vertical (componente meridiana $\xi$ e componente primeiro vertical $\eta$ ) (COSTA, 1999).

O estabelecimento das coordenadas geodésicas no ponto origem (Datum) e do azimute inicial era feita via aplicação das chamadas equações de orientação que permitem relacionar quantidades geodésicas e quantidades astronômicas conhecendo-se as componentes do desvio da vertical. Assim, no ponto origem era feita a determinação das coordenadas astronômicas (latitude $\Phi$ e longitude $\Lambda$ ) e do azimute astronômico $\left(A_{\mathrm{a}}\right)$ 
de uma direção com origem no Datum, e estas quantidades astronômicas eram convertidas para quantidades geodésicas através do conhecimento ou arbítrio das componentes do desvio da vertical, conforme Eq. (2), Eq. (3) e Eq. (4) (GEMAEL, 1999):

$$
\begin{gathered}
\xi=\Phi-\varphi \\
\eta=(\Lambda-\lambda) \cos \varphi \\
\eta=\left(A_{a}-A\right) \cot \varphi
\end{gathered}
$$

onde $A$ é o azimute geodésico da direção considerada. Igualando a Eq. (3) e a Eq. (4) obtêm-se a Eq. (5), conhecida como Equação de Laplace que permite converter um azimute astronômico em um azimute geodésico:

$$
A=A_{a}-(\Lambda-\lambda) \sin \varphi
$$

A realização do SGR clássico era feita por meio do estabelecimento de redes geodésicas horizontais a partir de técnicas de levantamentos geodésicos como triangulação, trilateração e poligonação. A rede tinha característica bidimensional, onde a partir do ponto origem mediam-se direções e/ou distâncias para o cálculo das coordenadas geodésicas $(\varphi \mathrm{e} \lambda)$ dos demais vértices da rede. As altitudes dos vértices eram determinadas com uma precisão relativa inferior à das coordenadas horizontais, por exemplo, através de nivelamento trigonométrico. Tais altitudes tinham a função de propiciar elementos para redução das bases (medidas sobre a superfície física da Terra) ao elipsoide de referência.

No Brasil, desde o início do estabelecimento do Sistema Geodésico Brasileiro (SGB), na década de 1940, o país adotou dois referenciais com características clássicas: Córrego Alegre e SAD69. O SGB caracteriza-se por toda a infraestrutura geodésica necessária à localização e representação cartográfica em território brasileiro, seu estabelecimento e manutenção são atribuições do IBGE (Instituto Brasileiro de Geografia e Estatística) (IBGE, 2000).

O SGR Córrego Alegre foi oficialmente adotado pelo Brasil da década de 1950 até a década de 1970. Sua definição utiliza como superfície de referência o Elipsoide Internacional de Hayford de 1924, com semieixo maior $a=6378388 \mathrm{~m}$ e achatamento $f=1 / 297$ (IBGE, 1996). O posicionamento e orientação do elipsoide deu-se de maneira totalmente arbitrária, ou seja, estabelecendo-se valores nulos para a altitude geoidal e para as componentes do desvio da vertical no Datum (vértice Córrego Alegre em MG). Na época era a única forma de realização possível na prática. Neste caso, com a imposição do valor nulo para as componentes do desvio da vertical no Datum, as coordenadas geodésicas deste vértice ficaram iguais às suas coordenadas astronômicas (IBGE, 1996):

Latitude $\varphi=\Phi=19^{\circ} 50^{\prime} 14,91^{\prime \prime} \mathrm{S}$ e

Longitude $\lambda=\Lambda=48^{\circ} 57^{\prime} 41,98^{\prime \prime} \mathrm{W}$,

A altitude ortométrica $(H)$ do vértice Córrego Alegre é $683,81 \mathrm{~m}$ e com a altitude geoidal nula considera-se que $H=h$. Devido à orientação arbitrária, existia uma boa adaptação elipsoide-geoide na região de Minas Gerais e São Paulo, porém distanciando-se da origem, as discrepâncias ficavam bastante evidenciadas.

O SAD69 (South American Datum 1969) foi oficialmente adotado no país no final da década de 1970 até fevereiro de 2005 quando foi substituído pelo SIRGAS. Em sua definição adotou-se como modelo geométrico da Terra o Elipsoide de Referência Internacional de 1967, definido pelos parâmetros semieixo maior $a=6378160,000 \mathrm{~m}$ e com achatamento (1/298,247167427) aproximado para o valor $f=1 / 298,25$ (IBGE, 1998). O posicionamento e a orientação do elipsoide deram-se de forma parcialmente arbitrária, determinando-se os valores das componentes do desvio da vertical (componente meridiana $\xi=0,31$ " e componente primeiro vertical $\eta=-3,52 ")$ e estabelecendo-se valor nulo para a altitude geoidal no Datum (vértice Chuá em MG). Através de uma determinação astronômica em Chuá e conhecendo-se os valores das componentes $\xi$ e $\eta$ foi possível calcular as coordenadas geodésicas do vértice por meio das equações de orientação apresentadas anteriormente (Eq. (2), (3), (4) e (5)). As coordenadas do vértice Chuá podem ser visualizadas na Tabela 1: 
Tabela 1 - Coordenadas do Vértice Chuá.

\begin{tabular}{l|c|c}
\hline \multicolumn{1}{c|}{ Coordenada } & Astronômica & Geodésica \\
\hline Latitude & $19^{\circ} 45^{\prime} 41,34^{\prime \prime} \mathrm{S} \pm 0,05^{\prime}$, & $19^{\circ} 45^{\prime} 41,6527^{\prime} \mathrm{S}$ \\
Longitude & $48^{\circ} 06^{\prime} 07,80^{\prime \prime} \mathrm{W} \pm 0,08^{\prime}$, & $48^{\circ} 06^{\prime} 04,0639^{\prime \prime} \mathrm{W}$ \\
Azimute ao vértice Uberaba & $271^{\circ} 30^{\prime} 05,42^{\prime \prime} \pm 0,21^{\prime \prime}$ & $271^{\circ} 30^{\prime} 04,05^{\prime}$ \\
(contado a partir do Sul) & \multicolumn{2}{|c}{$N=0 \mathrm{~m}$} \\
\hline Altitude geoidal & \multicolumn{2}{|c}{$\mid$} \\
\hline
\end{tabular}

Fonte: FISCHER (1973).

Neste caso procurou-se posicionar e orientar o elipsoide de forma a obter uma boa adaptação entre a superfície do elipsoide e o geoide na América do Sul e, principalmente, de forma a obter um melhor ajustamento entre as altitudes elipsoidais e ortométricas nas bordas oceânicas (IBGE, 2000).

De forma geral, a materialização do SGB, até o início da década de 90 , foi obtida pelos procedimentos clássicos de triangulação e poligonação, tendo como observações básicas: direções horizontais, ângulos verticais, distâncias e valores astronômicos - de coordenadas e azimutes (OLIVEIRA, 1998) que implicavam em precisões relativas na ordem de 1:50.000 a 1:100.000 ou 20ppm a 10ppm (ppm - partes por milhão), além de pontos estabelecidos com o sistema TRANSIT. A utilização do sistema TRANSIT iniciou-se no Brasil na década de 1970, quando foram realizadas observações Doppler em estações da rede geodésica fundamental com a finalidade de estimar parâmetros de transformação entre o SAD 69 e o NSWC $9 Z 2$ (que era o sistema de referência associado às efemérides precisas do sistema TRANSIT) (CASTAÑEDA, 1986). Posteriormente foram também estabelecidas estações na região amazônica onde não era viável a execução dos levantamentos geodésicos clássicos. Finalmente, em 1991 o IBGE passou a adotar o GPS (Global Positioning System) de forma sistemática em seus levantamentos geodésicos visando a densificação da rede horizontal (COSTA, 1999).

A partir do final da década de 1980 e na década de 1990, o uso cada vez mais frequente do GPS para posicionamento e as distorções existentes nas Redes Geodésicas Fundamentais de características clássicas, evidenciaram as inconsistências existentes entre os SGRs clássicos e os sistemas internacionais de referência baseados na adoção de elipsoides geocêntricos. Além disto, as técnicas de posicionamento geodésico, principalmente as baseadas em satélites que são capazes de fornecer diretamente as três coordenadas $(\varphi, \lambda, h)$, atingiram já em seus primórdios precisões relativas na ordem de $1 \mathrm{ppm}$ ou melhor, o que tornou necessária a adoção de sistemas de referência que possibilitassem um georreferenciamento global, de forma a compatibilizar e possibilitar a integração das informações internacionalmente e que considerassem ainda a variação temporal das coordenadas de acordo com a dinâmica terrestre.

\subsection{Aspectos modernos da definição e realização de um Sistema Geodésico de Referência}

Um SGR moderno baseia-se na adoção de um elipsoide de revolução cuja origem coincide com o centro de massas da Terra em dada época (geocentro) e cujo posicionamento e orientação são feitos em relação à Terra como um todo, caracterizando assim um sistema geocêntrico. $\mathrm{O}$ elipsoide de referência é assumido como tendo sua superfície equipotencial (elipsoide de nível) como é pressuposto no denominado modelo Terra Normal, o qual estabelece que o elipsoide de referência tem a mesma massa e velocidade angular da Terra e sua superfície é equipotencial. Este modelo é base para o estabelecimento do esferopotencial (soma do potencial gravitacional da Terra Normal com o potencial centrífugo que é o mesmo da Terra Real) e da gravidade normal. Tal modelo é associado aos parâmetros definidores dos SGRs convencionais, com o exemplo apresentado para o GRS80 (Geodetic Reference System, 1980) na Tabela 2. Diferentes SGRs têm, evidentemente, diferentes parâmetros que devem ser considerados nas conversões (Constante Gravitacional Geocêntrica $G M$, raio equatorial $a$, fator dinâmico de forma contido no coeficiente $J_{2}$ do geopotencial e velocidade angular da Terra $\omega$ ). Associa-se também um terno cartesiano tridimensional com origem no geocentro, orientação equatorial e escala métrica. Assim a posição tridimensional de qualquer ponto na superfície física da Terra pode ser representada pelas coordenadas $(\varphi, \lambda, h)$ ou $(X, Y, Z)$.

O modelo de referência recomendado pela Associação Internacional de Geodésia (IAG) é o GRS80 cujos parâmetros, geométricos e físicos podem ser visualizados na Tabela 2: 
Tabela 2 - Parâmetros definidores do GRS80.

\begin{tabular}{l|c|c}
\hline \multicolumn{1}{c|}{ Constante } & Valor & Descrição \\
\hline $\mathrm{GM}$ & $3,986005 \times 10^{14} \mathrm{~m}^{3} \mathrm{~s}^{-2}$ & Constante gravitacional geocêntrica \\
$\mathrm{a}$ & $6378137 \mathrm{~m}^{-3}$ & Raio equatorial da Terra (semieixo maior) \\
$\mathrm{J}_{2}$ & $1,08263 \times 10^{-3}$ & Fator dinâmico de forma \\
$\omega$ & $7,292115 \times 10^{-5} \mathrm{rads}^{-1}$ & Velocidade angular \\
\hline
\end{tabular}

Fonte: IERS (2010).

Cabe ser destacado que as constantes geodésicas fundamentais apresentadas na Tabela 2 envolvem aspectos geométricos e físicos. Enquanto o semieixo maior $a$ advém de determinações métricas indiretas que conduzem a precisões relativas melhores que $1 \mathrm{ppb}$ (parte por bilhão), a constante gravitacional geocêntrica $G M$ (produto da massa da Terra incluída sua atmosfera pela constante gravitacional universal) advém da análise do movimento orbital de satélites com órbitas estáveis o suficiente para sob a ação gravitacional da Terra atingir precisão na ordem de $1 \mathrm{ppb}$. Tal é o caso das missões SLR coordenadas pelo International Laser Ranging Service (ILRS, 2000). O fator dinâmico de forma $J_{2}=-C_{20}$ é um coeficiente adimensional do desenvolvimento do geopotencial em harmônicos esféricos, obtido da análise do movimento orbital de satélites estáveis sob a ação gravitacional da Terra. Este coeficiente, na atualidade, pode ser obtido com precisão melhor que 1ppb. A velocidade angular da Terra é avaliada a partir de métodos radio astronômicos baseados na observação de quasares com estabilidades temporais que podem, para efeitos práticos, materializar um referencial inercial. Tais observações são efetivadas com a técnica VLBI baseada em rede global de radiotelescópios que possuem resoluções melhores que $10^{-4} \operatorname{arcsec}$ (segundos de arco) ou 0,1 mas (miliarcsec). O tempo, envolvido nas determinações dos parâmetros referidos é baseado em relógios atômicos com estabilidade de $10^{-14}$ do segundo ou melhor sobre períodos de um ou mais anos.

Atualmente, o SGR global ITRS é entendido como base para a hierarquização das materializações continentais, nacionais e regionais de referencial geodésico para as aplicações multifinalitárias. Ele é materializado através de uma rede de estações fundamentais distribuídas pelo planeta (poliedro de estações) com coordenadas geodésicas tridimensionais conhecidas em uma época de referência. Este poliedro é então o ente fundamental a ser orientado em relação a um referencial celeste dito inercial. Essas coordenadas possuem um desvio padrão associado, são acompanhadas de suas respectivas velocidades e podem ser comparadas com as realizações ITRF anteriores. A determinação das coordenadas das estações é feita via rastreio GNSS e também acompanhadas via uma combinação de soluções provenientes de diferentes técnicas espaciais tais como VLBI e SLR por exemplo.

O IERS (International Earth Rotation and Reference Systems Service) tem como uma de suas atribuições estabelecer o vínculo do poliedro de estações ITRF com um referencial celeste inercial. A relação do referido poliedro com o International Celestial Reference System (ICRS), baseado em quasares, gera os denominados EOP (IERS Earth Orientation Parameters - Parâmetros de Orientação da Terra), os quais dimensionam a rotação real da Terra e suas irregularidades em relação ao ICRS. Os EOPs são (IERS, 2020): Tempo Universal corrigido do movimento do polo (TU1), baseado na rotação da Terra cuja instabilidade gera variações na duração do dia que é descrita pelo parâmetro LOD (length of day) informado pelo IERS; as Coordenadas do Polo celeste das efemérides $x$ e $y$ (CEP - Celestial Ephemeris Pole) onde o eixo $x$ aponta para o meridiano zero do ITRF e o eixo $y$ aponta para o meridiano com longitude $90^{\circ} \mathrm{W}$; Offsets do Polo Celeste que são descritos pelos modelos de precessão e nutação da IAU (International Astronomical Union). As diferenças observadas com respeito a posição do polo celeste convencional definido nos modelos são monitoradas e reportadas pelo IERS.

Estes aspectos são fundamentais para a definição dos chamados sistemas de referência modernos e sua implementação. Nesse sentido, pode-se afirmar que a Geodésia, em essência, deve ocupar-se com três tipos de sistemas de referência:

a) um sistema de referência celeste ou inercial, fixo no espaço, que fornece as coordenadas de objetos no espaço, como por exemplo, estrelas, quasares e satélites artificiais;

b) um sistema de referência terrestre geométrico, solidário com a Terra, que fornece as coordenadas de pontos sobre a superfície física da Terra, e

c) um sistema altimétrico, vinculado ao campo da gravidade (ou espaço do geopotencial). 
É importante destacar que a partir de uma única definição do sistema de referência pode-se ter diferentes realizações do mesmo. As diferentes realizações do referencial se devem por exemplo: a evolução dos equipamentos, novas modelagens no processamento dos dados, adoção de diferentes métodos de ajustamento, efeitos geodinâmicos sobre a rede e uso de maior período de dados no processamento; e isso gera novas coordenadas para as estações.

\subsubsection{SISTEMA DE REFERÊNCIA CELESTE CONVENCIONAL, SISTEMA DE REFERÊNCIA CELESTE INTERNACIONAL}

O Sistema de Referência Celeste Convencional (CCRS - Conventional Celestial Reference System) é também denominado de referencial equatorial ou uranográfico (Figura 1). É constituído por um terno cartesiano não girante, ou seja, por eixos não girantes em relação a objetos que possam ser considerados fixos no espaço. $\mathrm{O}$ eixo $\mathrm{X}$ está sobre o plano do Equador celeste e aponta para o ponto vernal numa determinada época; o eixo $\mathrm{Z}$ aponta para o Polo Norte Celeste e o eixo Y, no plano equatorial, torna o terno dextrogiro. As posições de pontos no espaço, como estrelas e quasares, são descritas, neste referencial, por meio das coordenadas ascensão reta $(\alpha)$ e declinação $(\delta)$. No entanto, os satélites artificiais têm sua posição no espaço descrita em função do tempo, neste referencial, por meio de coordenadas cartesianas (X, Y, Z).

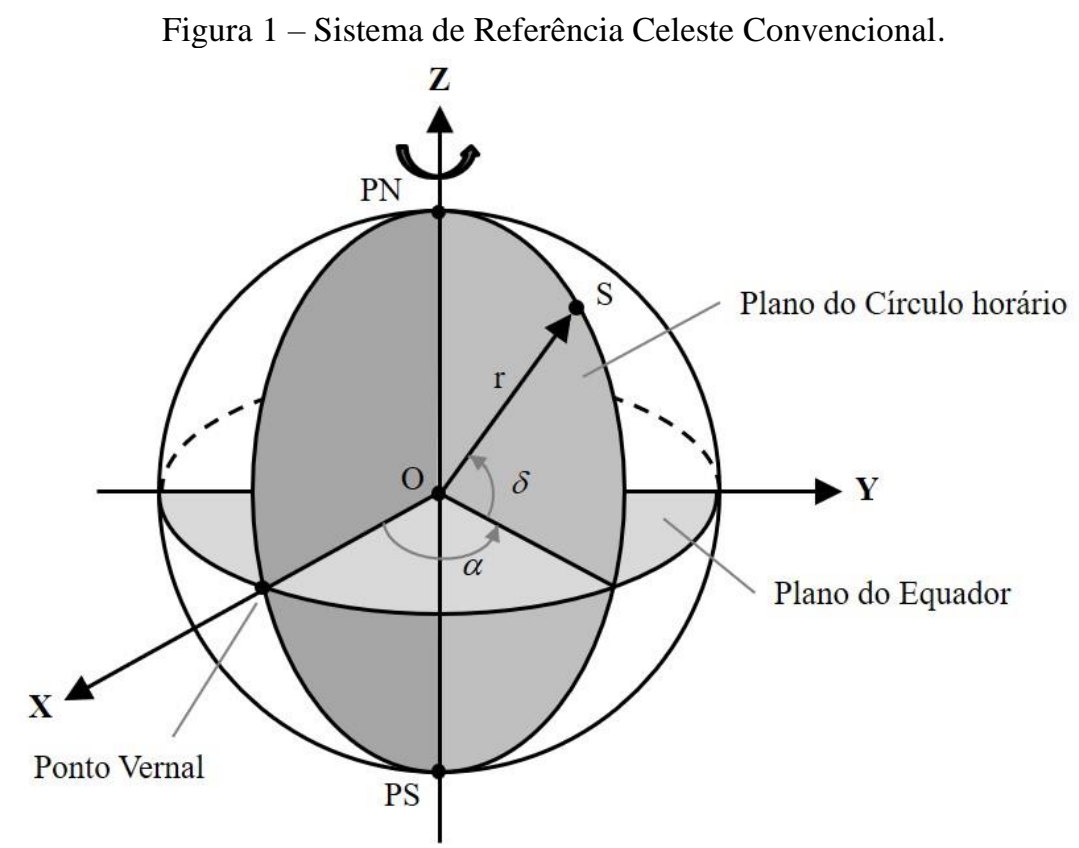

Fonte: Adaptada de Torge e Muller (2012).

O Sistema de Referência Celeste Internacional (ICRS - International Celestial Reference System) tem sua orientação estabelecida na época J2000. A época J2000 refere-se ao dia Juliano $1^{\circ}$ de janeiro de 2000, $12 \mathrm{~h}$ do Tempo Universal (12h TU).

Até o final de 1997, a realização do referencial celeste era dada por um catálogo de coordenadas equatoriais (ascensão reta e declinação) de um conjunto de 1535 estrelas. Este catálogo é denominado de FK5 e as coordenadas têm uma incerteza da ordem de 20 a 30 mas (mili arc seconds). O ICRF (International Celestial Reference Frame) substituiu oficialmente o FK5 em 01/01/1998 e é composto por um conjunto de coordenadas equatoriais de fontes de rádio extragalácticas (quasares) determinadas com VLBI (SEEBER, 2003; TORGE; MULLER, 2012).

O ICRS conta com três realizações:

a) ICRF1 (1998) é formado pelas coordenadas de 608 quasares na época 2000,0 com uma incerteza de 0,5 mas;

b) ICRF2 (2009) é formado pelas coordenadas de 3414 quasares na época 2000,0, esta realização 
conta com uma série temporal de 30 anos de observações VLBI;

c) ICRF3 (2019) é formado pelas coordenadas de 4536 quasares na época 2000,0 com um número significativo de quasares com incerteza em posição abaixo de 0,1 mas.

\subsubsection{SISTEMA DE REFERÊNCIA TERRESTRE CONVENCIONAL, SISTEMA DE REFERÊNCIA TERRESTRE INTERNACIONAL}

O Sistema de Referência Terrestre Convencional (CTRS - Conventional Terrestrial Reference System) (Figura 2) é um sistema fixo à Terra, ou seja, rotaciona e translada com ela. É um sistema geocêntrico onde a origem do referencial coincide com o centro de massas da Terra numa dada época. O terno cartesiano é orientado de forma que o plano XZ contém o meridiano médio de Greenwich numa dada época. $\mathrm{O}$ eixo $\mathrm{Z}$ aponta para o CIO (Conventional International Origin) também chamado CTP (Conventional Terrestrial Pole) que corresponde a posição média do polo durante os anos de 1900 a 1905 e o eixo Y torna o terno dextrogiro (SEEBER, 2003; TORGE; MULLER, 2012).

Figura 2 - Sistema de Referência Terrestre Convencional.

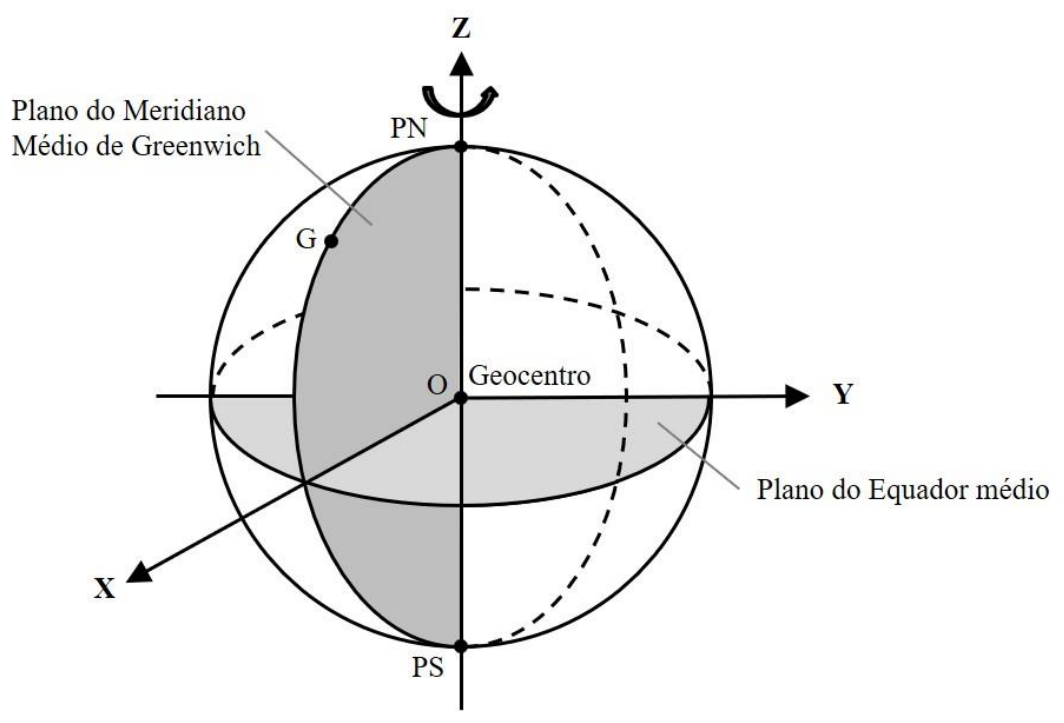

Fonte: Adaptada de Torge e Muller (2012).

O Sistema de Referência Terrestre Internacional (ITRS - International Terrestrial Reference System) é definido através de um conjunto de convenções da IAG e da IAU (International Astronomical Union) para o estabelecimento do que se denomina a vanguarda científica dos sistemas de referência terrestres convencionais. Sua origem é no centro de massa da Terra incluindo o oceano e a atmosfera, tem como escala o metro (SI - Sistema Internacional), sua orientação é coincidente com a do Bureau Internationale de l'Heure (BIH) na época 1984,0 ( \pm 3mas), utiliza como modelo de Terra o elipsoide do GRS80 e sua evolução temporal em orientação é garantida pela introdução da condição NNR (No Net Rotation) - rede que não rotaciona em relação ao movimento tectônico horizontal da crosta.

A materialização ou realização do ITRS é denominada de ITRF (International Terrestrial Reference Frame) e consiste em um conjunto de coordenadas, velocidades e suas respectivas precisões para um grupo de estações determinadas com diferentes técnicas espaciais (por exemplo: VLBI, SLR, LLR, GPS e DORIS). A IAG possui serviços científicos dedicados a cada uma das técnicas espaciais de observação e cada serviço tem estrutura própria para processar os dados de cada técnica. São exemplos de serviços da IAG: o IGS International GNSS Service; o ILRS - International Laser Ranging Service e o IVS - International VLBI Service for Geodesy and Astrometry. O IERS faz a combinação final das diferentes soluções gerando o ITRFyyyy, onde yyyy se refere ao ano da realização do referencial. Além disso o IERS fornece os parâmetros de orientação da Terra (EOP - Earth Orientation Parameters) para realizar a conexão entre os sistemas de referência celeste e terrestre.

As diferentes realizações do ITRS compreendem: ITRF89; ITRF90; ITRF91; ITRF92; ITRF93; 
ITRF94; ITRF96; ITRF97; ITRF2000; ITRF2005; ITRF2008 e o ITRF2014 (ALTAMIMI et al., 2016).

\section{SISTEMAS E REDES GEODÉSICAS VERTICAIS FUNDAMENTAIS}

Altitudes com sentido prático são aquelas determinadas por operações de nivelamento e vinculadas ao campo da gravidade da Terra. Assim, o conceito de desnível associado ao posicionamento vertical, também deve ter significado físico, onde os desníveis referenciados tenham correspondência biunívoca com diferenças de potencial do campo da gravidade. Estes são os desníveis e as altitudes que interessam na concepção de obras como barragens, dutos e canais, por exemplo. Estes aspectos não eram atendidos pelas altitudes conhecidas ao longo das redes geodésicas clássicas de triangulação, trilateração e poligonação, de forma que estas eram costumeiramente denominadas de redes horizontais. As redes verticais clássicas, baseadas em nivelamento geométrico, com seções, linhas e circuitos de nivelamento a partir de um Datum Vertical (DV) até o presente ainda persistem como redes independentes das horizontais e mesmo das redes tridimensionais modernas baseadas nas realizações ITRF e suas densificações. Mesmo com o advento dos métodos de posicionamento global baseados em tecnologias espaciais com altitudes elipsoidais facilmente obtidas, estas, em geral não atendem a uma grande gama de aplicações. Mesmo as altitudes advindas das redes verticais clássicas não atendiam de forma plena a referida relação biunívoca com os desníveis geopotenciais, uma vez que o vínculo com o campo da gravidade era, em geral, estabelecido de forma parcial a partir de um campo da gravidade teórico. Na sequência, este aspecto será discutido de forma mais pormenorizada já que também as redes verticais clássicas ainda predominam como redes nacionais e trazem ainda restrições quanto às suas integrações em um sistema geodésico de referência vertical único no planeta. Ainda merecem reflexões os aspectos manifestados nas seções precedentes: é fundamental que o referencial geométrico tridimensional e o das altitudes com significado físico sejam integrados em um único SGR. Para tanto, ambos devem convergir para uma realização global única. Neste particular, os referenciais verticais devem abandonar seus caráteres locais ou regionais para uma integração global no espaço do geopotencial, conforme será discutido nas seções a seguir.

\subsection{Aspectos clássicos relacionados ao Datum Vertical e Redes Geodésicas Verticais}

Em geral, a realização do DV é vinculada ao Nível Médio do Mar (NMM), salvo aqueles dos países que não tenham costas marítimas. O NMM é obtido por longas séries de observação maregráfica e é vinculado a uma Referência de Nível (RN) situada próxima do marégrafo. Simplificadamente, a variação do nível do mar instantâneo (local) com respeito ao zero do marégrafo é monitorada. Com os dados obtidos do monitoramento, calcula-se o nível médio do mar local e determina-se a altitude de uma RN nas proximidades do marégrafo (VANÍČEK; KRAKIWSKY, 1986). Nesta definição clássica para o estabelecimento de um Datum vertical assumia-se o NMM como coincidente com o geoide. Tal fato é amplamente rechaçado na atualidade, tal que o monitoramento maregráfico costeiro atual conduz às referências expressas na Figura 3.

Figura 3 - Realização de Datum Vertical com a determinação do NMM e relações espaciais com outras referências.

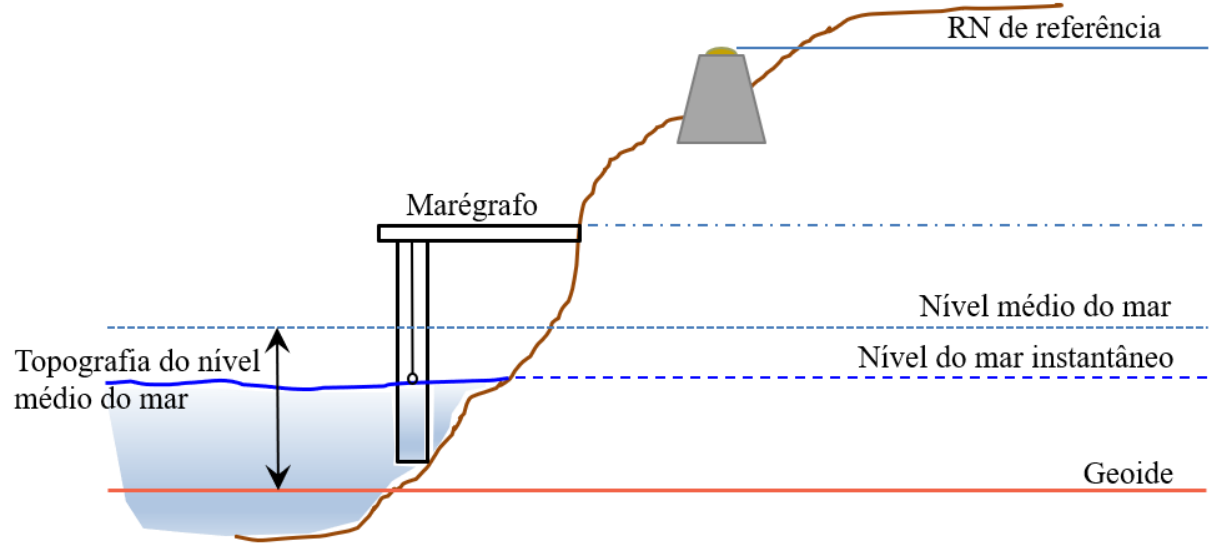

Fonte: Os autores (2020). 
A partir do estabelecimento do DV e sua conexão a uma ou mais RNs na região do marégrafo são determinadas as altitudes das demais estações que materializam a Rede Geodésica Vertical (RGV). As RGVs fundamentais são estabelecidas, na sua maior parte, por nivelamento geométrico. Assim, as altitudes dos outros pontos da RGV são determinadas a partir dos desníveis obtidos com nivelamento geométrico e referidas à RN situada próxima ao marégrafo. Nestas redes podem ser introduzidas correções gravimétricas (teóricas ou de observações) para a realização de correções dos efeitos do geopotencial sobre o nivelamento e assim dotar as altitudes de algum significado físico. Estes aspectos serão discutidos na sequência. De acordo com Vaníček e Krakiwsky (1986), as redes verticais clássicas, com correções de natureza física, propagam altitudes com precisão estimada de acordo com a Eq. (6):

$$
\sigma_{H}=1,8 \times 10^{-3} \times S^{2 / 3} \text { metros }
$$

onde $S$ é a distância nivelada em quilômetros.

A posterior interligação, com base em nivelamento geométrico, entre diferentes marégrafos de um país e a interligação entre redes verticais de países vizinhos, apontam, em geral, diferenças nas altitudes niveladas para um mesmo ponto que não podem ser atribuídas apenas como erros nas operações de nivelamento; com isso a conexão entre diferentes redes verticais locais é, em geral, inconsistente. Essas diferenças estão relacionadas ao próprio processo de nivelamento e também ao estabelecimento do nível de referência de cada rede vertical (NMM) e suas variações temporais e espaciais, conforme apresentado na Figura 4.

Aqui a principal consideração a ser feita é a de que o NMM é obtido em uma estação maregráfica após um certo número de anos de observações, valendo para aquele local e para uma dada época, pois o NMM varia de um ponto para outro e no mesmo ponto em função do tempo (GEMAEL, 1999). Assim, o uso do NMM como superfície de referência para as altitudes era amplamente aceito. Porém, sob uma visão moderna, é reconhecido que o NMM observado em qualquer ponto dos oceanos não pode ser considerado coincidente com um geoide global (PAN; SJÖBERG, 1998). Ou seja, cada DV realizado pelo NMM é referido a uma superfície equipotencial particular ("geoide" local). Neste sentido, cabe destacar que este fato já era reconhecido na definição de geoide de Gauss-Listing (LISTING, 1873 apud HECK, 2004) onde estabeleceram que "o geoide é a superfície equipotencial do campo da gravidade, com geopotencial $W_{0}$, melhor ajustada, no sentido dos mínimos quadrados, ao NMM em um sentido global". Tal condição fundamenta a definição oceanográfica do geoide, que é a definição de geoide mais aceita na atualidade em vista da facilidade de sua realização a partir da altimetria por satélites sobre os oceanos, onde cada ponto onde se avalia o NMM pode ter seu geopotencial $W$ determinado em um SGR global. A definição oceanográfica baseia-se na mesma hipótese de Gauss-Listing reconhecendo que o equilíbrio quase-estacionário do NMM é determinado a partir de condições de equilíbrio geostrófico onde atuam forçantes dinâmicas e outras variáveis físicas tal que a superfície global do NMM não é equipotencial (DE FREITAS et al., 2002). Cada ponto de observação possui um valor de geopotencial $W$ específico. Considerando $\sigma$ a superfície dos oceanos, esta definição pode ser expressa pela Eq. (7) como:

$$
\int_{\sigma}\left(W_{0}-W\right)^{2} d \sigma=\min
$$

O NMM possui, globalmente uma discrepância com relação ao geoide global chamada de Topografia do Nível Médio do Mar (TNMM) (Sea Surface Topography - SST) (Figura 4). A TNMM é causada por variações na pressão atmosférica, correntes, entre outros fatores (SEEBER, 2003) e pode alcançar valores de até dois metros (HECK; RUMMEL, 1990; FENOGLIO, 1996; SEEBER, 2003). 
Figura 4 - Visão moderna relacionada ao Datum Vertical.

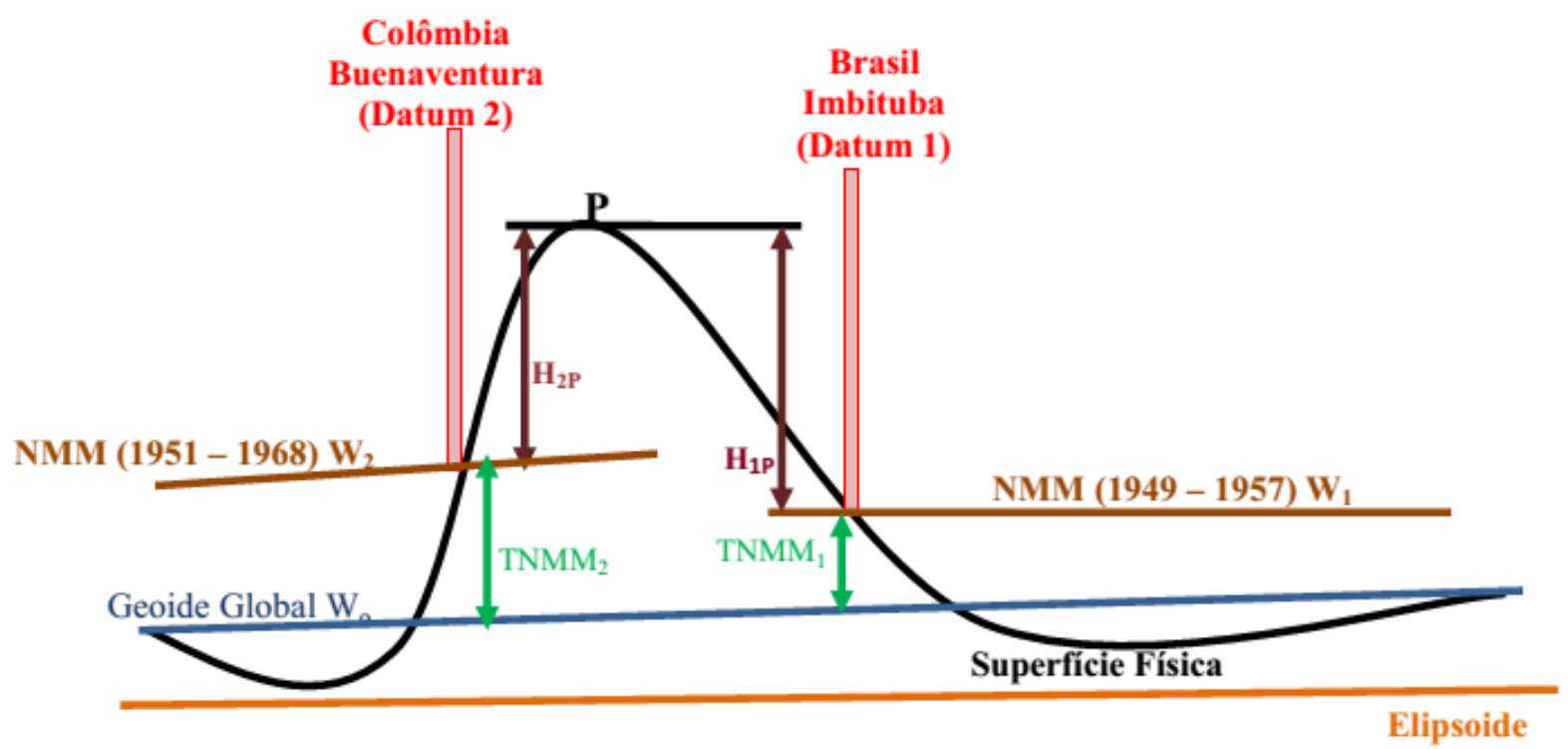

Fonte: Adaptada de IBGE (2002).

De forma geral, os aspectos clássicos relacionados com o estabelecimento do DV e com a materialização da RGV não permitem o intercâmbio de dados entre diferentes países. Colaboram para isso: a determinação do DV a partir do NMM em um ponto e numa dada época; o fato de alguns países possuírem mais de um DV devido à impossibilidade de densificação da RGV na totalidade do país devido à sua configuração geográfica; a não consideração de variações temporais tanto na definição do DV quanto no estabelecimento da rede; diferentes formas de estabelecimento da rede vertical que levaram em conta ou não correções gravimétricas; entre outros aspectos. A solução para essas questões vem com a definição de uma superfície de referência global e a definição de altitudes com significado físico, conforme abordado no próximo item.

A definição de altitude com significado físico está relacionada com uma diferença de potencial da gravidade (geopotencial), por exemplo, na Figura 5 a altitude de B está relacionada com a diferença de potencial $W_{0}-W_{4}$ :

Figura 5 - Visão moderna relacionada ao nivelamento geométrico.

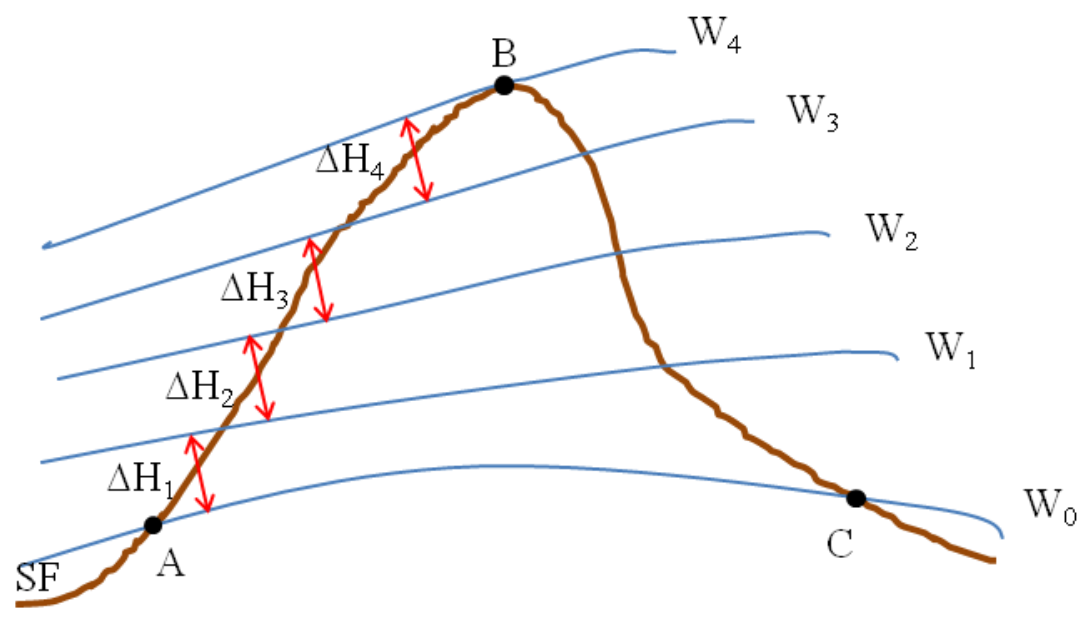

Fonte: Os autores (2020).

Essa diferença de potencial da gravidade é chamada de número geopotencial $(C)$. O número geopotencial em um ponto $\mathrm{P}\left(C_{P}\right)$ na superfície física da Terra é definido então como a diferença entre o geopotencial no geoide $\left(W_{0}\right)$ e o geopotencial no ponto $\left(W_{P}\right)$ conforme a Eq. (8) (HOFMANN-WELLENHOF; MORITZ, 2005): 


$$
C_{P}=W_{0}-W_{P}
$$

De forma prática o número geopotencial pode ser obtido associando-se nivelamento geométrico de precisão com gravimetria. Assim, o número geopotencial é calculado a partir de valores de desníveis $(\Delta H)$ e valores médios de gravidade $(\bar{g})$ em cada seção nivelada sobre a superfície física da Terra, de acordo com a Eq. (9):

$$
C_{P}=\sum \bar{g} \Delta H
$$

Porém não se adotam valores do número geopotencial para representar diretamente a coordenada vertical de um ponto, pois estes são de difícil interpretação e visualização. Vale ressaltar que o potencial da gravidade tem unidade $\left[\mathrm{m}^{2} \mathrm{~s}^{-2}\right]$, decresce com o aumento da altitude e no NMM seu valor não é nulo. Uma altitude com significado físico $\left(H_{\mathrm{P}}\right)$ pode ser obtida, conforme mostra a Eq. (10), dividindo o número geopotencial por um valor particular da gravidade $(G)$ :

$$
H_{P}=\frac{C_{P}}{G}
$$

Vale ressaltar que o fato do cálculo do número geopotencial estar associado com o nivelamento geométrico, faz com que a obtenção das altitudes esteja associada à definição do DV local. Nas redes verticais estabelecidas desta forma ainda permanece um efeito sistemático associado à definição do DV.

A guisa de ilustração, merecem ser mencionados aspectos de redes verticais clássicas na América do Sul. A maior parte dos países do continente estabeleceu seu DV entre as décadas de 1940 e 1950. No Brasil, no contexto do Sistema Geodésico Brasileiro (SGB), cerca de 95\% da Rede Vertical Brasileira (RVB) é vinculada ao DV realizado pelas observações maregráficas tomadas no Porto de Imbituba, no litoral do estado de Santa Catarina. O Datum Vertical Brasileiro (DVB) foi estabelecido em 1958, com base nas observações maregráficas realizadas entre os anos de 1949 e 1957. No entanto, uma parte da RVB situada no estado do Amapá é vinculada ao DV estabelecido no porto de Santana. A conexão destes dois segmentos da RVB é uma tarefa em andamento na atualidade (SANTACRUZ; DE FREITAS; LUZ, 2019).

A implantação da RVB iniciou em 1945, em Santa Catarina. Como nessa época o país ainda não possuía oficialmente um DV, a conexão da rede de nivelamento foi feita com o marégrafo de Torres no Rio Grande do Sul, em 1946. O DV de Torres teve caráter provisório, uma vez que foi definido com apenas um ano de observações do nível do mar (1919 - 1920), sendo substituído pelo DV de Imbituba em 1958 que contava com uma série temporal de observações do nível do mar mais longa (ALENCAR, 1990).

Até meados de 2018 a RVB era materializada exclusivamente por meio de nivelamento geométrico. As altitudes das RNs eram chamadas oficialmente de altitudes ortométricas. No entanto esta denominação não era correta, pois, as altitudes niveladas só recebiam correções gravimétricas teóricas para o não paralelismo das superfícies equipotenciais do campo da gravidade normal (teórico) tal que eram, na realidade, altitudes "normais ortométricas". Essas correções são calculadas com base no valor da gravidade normal (teórica), ou seja, não fazem uso de observações gravimétricas reais e são aplicadas diretamente aos desníveis medidos. A partir de 2018, o IBGE incorporou correções gravimétricas a toda a RVB e promoveu seu reajustamento com base em números geopotenciais. Desta forma, mesmo persistindo efeitos sistemáticos dos DVs nos dois segmentos da rede, os desníveis agora expressam efetivamente características físicas reais.

\subsection{Aspectos modernos relacionados ao Datum Vertical e Redes Geodésicas Verticais}

O Inter Commission Project ICP 1.2 - World Height System-Pilot Project (ICP1.2 - WHS-PP) da IAG foi desenvolvido até 2011 sob a perspectiva do Tema 1 do GGOS, buscando estabelecer os fundamentos de um sistema global de altitudes unificado (IDHE; SIDERIS, 2010). As conquistas e convenções propostas do ICP1.2 - WHS bem como as perspectivas na época são descritas por Sánchez (2012). A adoção global do 
GGOS pela comunidade internacional como uma das sustentações dos EOS foi recomendada pelas Nações Unidas durante sua Conferência Regional de Cartografia em Bangcoc - Ásia em novembro de 2012, destacando a necessidade do WHS. A consequência das atividades do GGOS/IAG desde 2003 e o termo 20112015 das ações do GGOS resultaram na Resolução No. 1 da IAG em julho de 2015: "Definition and realization of an International Height Reference System (IHRS)" a qual estabeleceu diversas condições e padrões para um novo Sistema Global de Altitudes totalmente vinculado ao espaço do geopotencial. A superfície única para referência das altitudes é fixada como a superfície do campo da gravidade com valor do geopotencial $W_{0}=62636853,4 \mathrm{~m}^{2} \mathrm{~s}^{-2}$. A coordenada vertical primária de cada ponto P na superfície física da Terra é o seu número geopotencial dado em função do negativo de sua diferença de potencial $C_{P}=-\Delta W_{P}=W_{0}-W_{P}$ em relação à referida superfície de referência (IAG, 2015). A IAG estabeleceu em 2016 o "Joint Working Group 0.1.2. on Strategy for Realization of the International Height Reference System (IHRS)" inserido no Tema 1 do GGOS. O Brasil, através do SIRGAS - Grupo de Trabalho III participa do JWG 0.1.2 desde sua criação.

\subsubsection{REDES VERTICAIS DE REFERÊNCIA NACIONAIS E O IHRS/IHRF}

Os principais aspectos a serem considerados no estabelecimento do IHRF dizem respeito à necessidade de integração das Redes Verticais de Referência Nacionais (RVRNs) existentes dentro da nova concepção trazida pelo IHRS. Assim é que a pluralidade de características das RVRNs envolvendo forma de realização, precisão, DVs particulares, associação ou não com a gravimetria para determinação de números geopotenciais, evolução temporal e suas manutenções, são aspectos relevantes a serem considerados em conjunto com a necessidade de novas observações geodésicas associadas. De Freitas (2015) apresenta uma visão geral a respeito da fundamentação e estratégias para a modernização das RVRNs no contexto do SIRGAS em atendimento aos preceitos do IHRS, do IHRF e do futuro GGRF. As ações entendidas como necessárias estão baseadas nos seguintes protocolos:

a) Definição de estratégias para realizar as redes existentes por meio de altitudes físicas $\left[H_{P}=\mathrm{f}\left(C_{P}\right)\right]$;

b) Vinculação das RVRNs com as estações GNSS contínuas do SIRGAS;

c) Integração das RVRNs no espaço do geopotencial para constituir a Rede Vertical de Referência do SIRGAS (RVRS);

d) Abordagens para referir a RVRS ao valor $W_{0}$ do IHRS;

e) Associação da RVRS a uma época de referência e modelagem das variações temporais das coordenadas verticais, $\mathrm{e}$

f) Planejamento de atividades para estabelecer um conjunto de estações IHRF/GGRF na região, base para referenciar adequadamente as RVRNs ao IHRS.

Uma síntese da base científica para aplicação dos protocolos referidos é mostrada na Figura 6, e discutida a seguir.

A relação entre o IHRF e a RVRN $(i)$ pode ser estabelecida quando a rede nacional é realizada com base em números geopotenciais na forma $C_{P i}=W_{0 i}-W_{P}$, onde $W_{0 i}$ é o geopotencial no $\mathrm{DV}_{i}$ e $W_{P i}$ é o valor do geopotencial no ponto $\mathrm{P}$ obtido pela associação da gravimetria às operações de nivelamento. Este número geopotencial $C_{P i}$ difere daquele $C_{P}$ referido à referência global $W_{0}$ por um valor expresso como o offset $(\delta W)$ no espaço do geopotencial, conforme a Eq. (11) (CARRIÓN, 2017):

$$
\delta W=W_{0}-W_{0 i}=W_{P}-W_{P i}
$$

O offset em unidade métrica correspondente é dado pela Eq. (12):

$$
\Delta H=\frac{\delta W}{\gamma_{0}}
$$


onde $\gamma_{0}$ é a gravidade normal no nível do elipsoide de referência, facilmente determinável por fórmulas matemáticas para cada SGR envolvido.

$\mathrm{Na}$ Eq. (13) observa-se que o potencial da gravidade teórica ou esferopotencial $(U)$, também facilmente determinável, relaciona-se, em um mesmo ponto, com o geopotencial da Terra real $\left(W_{P}\right)$ na forma:

$$
T_{P}=W_{P}-U_{P}
$$

onde $T_{P}$ refere-se ao potencial perturbador. O potencial perturbador manifesta as discordâncias da Terra real em relação à Terra normal à qual se atribui mesma massa e mesma velocidade angular da Terra real e é geometricamente relacionada ao elipsoide de referência do SGR. O potencial perturbador, é então foco central das determinações relacionadas com referenciais globais, sendo determinado pela solução do PVCG em cada ponto onde vise-se obter $W_{P}$. Estes aspectos envolvendo a relação entre as RVRNs e o IHRS com base na solução do PVCG, incluindo as características de cada DV nacional são sintetizados na Figura 6.

Figura 6 - Fluxograma da relação entre uma RVRN e o IHRS dentro de uma concepção moderna baseada em números geopotenciais e, portanto, no espaço do geopotencial.

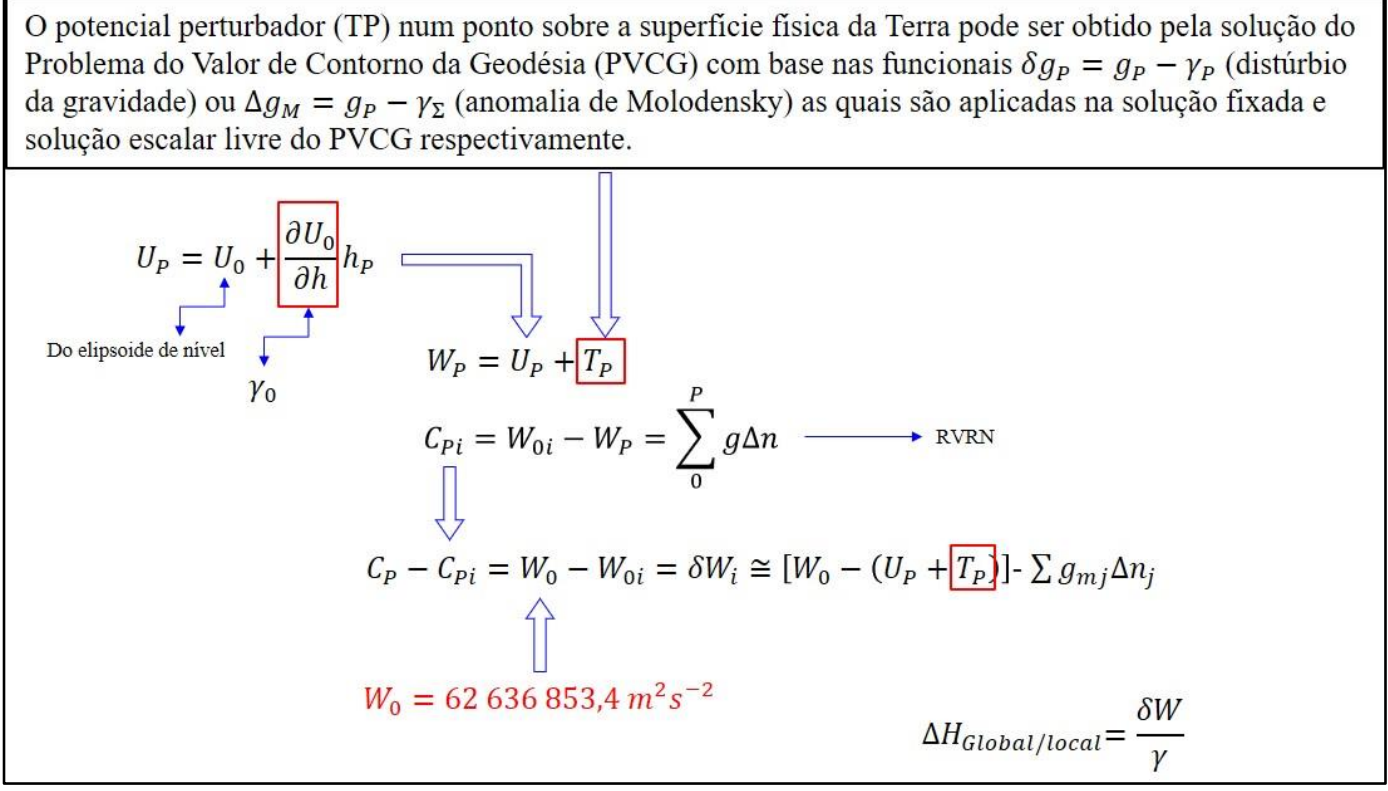

Fonte: Adaptada de Carrión (2017).

Aspectos dinâmicos das RVRs devem ser objeto de pesquisas intensas na década que ora se inicia. Os modelos de movimentos horizontais no ITRF são bem estabelecidos, descrevendo os efeitos tectônicos de deslocamentos horizontais. Estes movimentos, preditos em modelos geofísicos tal como o NNRNUVEL-1A (No Net Rotation - Northern University Velocity Model 1A), relacionam-se bem com modelos geodésicos de velocidade horizontais recentes desenvolvidos a partir de observações de redes de estações GNSS contínuas, como por exemplo o modelo VEMOS 2017 estabelecido com base na rede de estações SIRGAS-CON (DREWES; SÁNCHEZ, 2020). No entanto, para as redes verticais restam muitos desafios, já que todas as realizações ITRF não privilegiam modelos de deslocamentos verticais. Isto não é acidental pois a modelagem vertical é extremamente complexa. Esta além da modelagem de efeitos regulares, ou aqueles modelados globalmente na tectônica de placas, envolve outras modelagens globais/regionais/locais tais como o soerguimento pós-glacial, cargas hidrológicas sazonais ou não, e também efeitos de eventos sísmicos. Tais aspectos, que interferem na modelagem das RVRNs e suas manutenções são bem discutidos por MONTECINO et al. (2017), FERREIRA et al, (2019) e BRASSAROTE (2020) em trabalhos realizados em nosso continente, conforme indicado na Introdução. 


\section{SISTEMA GEODÉSICO DE REFERÊNCIA GLOBAL (GGRS/GGRF)}

Os EOS requerem referências estáveis no tempo e consistência global no referenciamento das informações. Tais informações, envolvendo o referenciamento espacial e físico das informações relacionadas com variáveis fundamentais ao monitoramento ambiental, como os movimentos tectônicos e redistribuições de massa, por diversos processos geofísicos no sistema Terra, foram atribuídas à Geodésia. Em atendimento a estas demandas, a Assembleia Geral das Nações Unidas adotou, em 26 de fevereiro de 2015, a resolução do Global Geodetic Reference Frame for Sustainable Development (A/RES/69/266) (UNITED NATIONS, 2015). O Sistema Geodésico de Referência Global (GGRS) envolve a definição de um conjunto de modelos físicos e matemáticos necessários para descrever as posições geométricas e físicas e a gravidade no espaço e ao longo do tempo. Sua materialização (GGRF) será dada pela integração de diferentes redes geodésicas de referência: ITRF, ICRF, o futuro IHRF e uma nova Rede Gravimétrica Global Absoluta. Ele visa estabelecer um sistema de referência comum para a geometria e o campo de gravidade da Terra, por meio da combinação de diferentes SGRs: Assim é que envolve o ITRS/ITRF, IHRS/IHR, o ICRS-ICRF e a Global Absolute Gravity Network (GAGN). A realização do GGRS passa pelas seguintes especificações (IAG, 2016):

a) Para o ponto físico $\mathrm{P}$, o potencial $W_{P}=W(X)$ é avaliado no vetor de posição $\boldsymbol{X}((X, Y, Z)$ ITRF $\equiv(\varphi, \lambda, h) \mathrm{ITRF})$

b) A unidade de tempo é o segundo e a unidade de comprimento é o metro, ambos no Sistema Internacional de Unidades (SI);

c) A altitude física é o $C_{P}$;

d) $\quad$ vetor de gravidade $g$ é o gradiente do geopotencial no ponto P;

e) A geometria e a gravidade são funções implícitas do tempo;

f) São necessários parâmetros fundamentais e convenções para o uso de modelos e procedimentos, tal como um modelo global do geopotencial (MGG) em harmônicos esféricos com resolução espacial e pontual compatível com as aplicações;

g) O ICRS fornece a base celeste para o GGRS, e

h) A relação entre o ITRS e o ICRS é descrita pelos EOP.

O GGRF baseia-se no preceito de uma rede fundamental de pontos terrestres de referência global e as redes nacionais devem ser integradas a esta. A materialização das estações de referência global deve envolver diferentes técnicas geodésicas além do GNSS mais nivelamento, como VLBI, SLR, DORIS, e outras técnicas globais possíveis. Esta integração tem como pressuposto fundamental, em todos os situs, a observação de gravidade absoluta com resolução mínima na ordem de 1 microGal e o vínculo à GAGN. Assim é que esta rede de estações GGRF deverá compreender (IAG, 2016):

a) Observatórios geodésicos fundamentais que empreguem todas as técnicas geodésicas espaciais co-localizadas com instrumentos gravimétricos, permitindo a ligação entre $\boldsymbol{X}, W$ e $g$,

b) Outras estações geodésicas que incluam também marégrafos de referência, pontos de referência de altitude e pontos gravimétricos co-localizados, sempre que for possível, com instrumentos geodésicos espaciais.

Todas as estações GGRF devem:

a) Funcionar continuamente, a longo prazo, para assegurar a estabilidade do GGRF;

b) Ser equipadas com tecnologia de observação de ponta, para produzir medições de quantidades geodésicas;

c) Serem monitoradas continuamente para detectar deformações superficiais da crosta,

d) Serem conectadas aos DVs para relacionar com precisão suas diferenças de geopotencial visando a sua unificação. 


\section{DESAFIOS E PERSPECTIVAS FUTURAS}

A definição e realização de SGRs que integrem geometria e campo da gravidade da Terra são essenciais para a vinculação de observações relacionadas à dinâmica do planeta e mudanças globais. São, desta forma, base fundamental para o estabelecimento dos EOS. Aqui faz-se necessário que as observações geodésicas sejam integradas a estruturas de referência com uma acurácia de $10^{-9}$ ou melhor. Uma questão importante nesse contexto é: como atingir e garantir essa acurácia?

Apesar da definição do GGRS e dos preceitos estabelecidos para sua realização (GGRF), como garantir a distribuição geográfica e a manutenção ao longo do tempo destas estações multitécnicas de forma a atingir os requisitos dos EOS?

Até 2015 um dos grandes desafios da Geodésia era o de definir e realizar uma superfície de referência global para as altitudes por meio de um valor de geopotencial $\left(W_{0}\right)$. Com esse valor definido, a tarefa atual está voltada para a determinação de estratégias que possibilitem a conexão das redes verticais clássicas a esta superfície de referência, eliminando assim as discrepâncias existentes entre os diferentes referenciais verticais. Esta não é uma tarefa fácil dada a não homogeneidade na distribuição de dados gravimétricos, diferentes estratégias utilizadas para o levantamento e processamento de dados, entre outros fatores. Neste contexto, uma das questões a serem respondidas relaciona-se a: qual é a melhor estratégia para esta conexão tendo em vista as bases de dados existentes?

O SIRGAS, desde 1997, vem atuando no sentido de estabelecer um Sistema Vertical de Referência para a América Latina e Caribe, e hoje dirige suas atividades de encontro aos requisitos internacionais para integração ao IHRS/IHRF. Porém há grandes vazios de informação gravimétrica e de nivelamento nos países membros. Em muitas situações os dados existem, porém, estão em meio analógico, sem metadados com informações relacionadas à qualidade, vínculos e histórico dos mesmos. O inventário destes dados é de extrema importância visando o estabelecimento de estratégias de integração e vínculo ao IHRS. Ganhos são obtidos com a aplicação de técnicas de posicionamento espacial, como o GNSS associado com gravimetria terrestre, dados de missões da altimetria por satélites e de missões gravimétricas e o uso de MGG. Assim, consistem em questões fundamentais a este respeito: como manter bancos de dados consistentes e atualizados com metadados adequados? Como prover treinamento adequado às pessoas que trabalham com esse tipo de informação? Estas são tarefas que devem ser realizadas de forma contínua no contexto do projeto SIRGAS.

É sabido que as deformações verticais atingem magnitudes superiores a tolerância estabelecida para a manutenção de um referencial vertical moderno. Assim é que aspectos desafiadores com relação ao referencial vertical referem-se ao seu acompanhamento temporal, respondendo às questões: como garantir a consistência do referencial ao longo do tempo? Como modelar essas variações que possuem uma componente cíclica dominante em algumas regiões? São relevantes as modelagens das variações lineares associadas com subsidência e soerguimento pós-glacial, os efeitos sazonais de cargas hidrológicas e efeitos cossísmicos e póssísmicos.

Estas questões refletem alguns dos desafios e perspectivas futuras da Geodésia rumo ao GGRS/GGRF. Refletem também os desafios da Geodésia como ciência capaz de prover a base necessária para o monitoramento do Sistema Terra, tarefa com impactos práticos amplos para a sociedade visando o desenvolvimento sustentável.

\section{CONSIDERAÇÕES FINAIS}

O advento da era espacial proporcionou uma revolução em termos de sistemas e redes geodésicas de referência. Os referenciais de características locais foram aos poucos sendo substituídos por referenciais globais. Outro aspecto importante é o fato de que não é mais possível separar aspectos puramente geométricos dos aspectos físicos da Terra e a criação dos EOS vem corroborar com essa afirmação. Monitorar o Sistema Terra, e todos os seus processos, com o objetivo de entender sua dinâmica e prover a base de conhecimento necessária para um desenvolvimento sustentável da sociedade é um dos grandes desafios atuais e a Geodésia é a ciência capaz de prover toda a base necessária para este monitoramento.

Como a concepção do GGRS/GGRF requer a integração entre o referencial terrestre, o celeste, um 
referencial com características físicas para as altitudes e a nova rede global de gravidade absoluta, pode-se afirmar que o estabelecimento e manutenção do referencial vertical é a tarefa que requer os maiores esforços. Apesar da definição do referencial, o IHRS, estar bem concebida, ainda se tem um longo caminho a ser percorrido para sua materialização, o IHRF.

A adoção de um valor convencional para o geopotencial $\left(\mathrm{W}_{0}\right)$ trouxe novas perspectivas para a Geodésia. Como os referenciais verticais ainda possuem características clássicas e os dados relacionados ao campo da gravidade da Terra carecem de distribuição espacial e qualidade homogêneas, será necessário estabelecer uma série de procedimentos padrão visando a integração ao referencial altimétrico global e o alcance da precisão necessária para o estabelecimento dos EOS. Nesse sentido, avanços têm sido alcançados com base na modelagem do potencial perturbador via a solução do PVCG.

A modelagem temporal das altitudes também é uma tarefa desafiadora, dada a necessidade de considerar tanto efeitos regulares quanto irregulares nessa modelagem. Tectônica de placas, soerguimento pósglacial, cargas hidrológicas e eventos sísmicos, são exemplos de efeitos que interferem na modelagem temporal das RVRNs.

Da mesma forma que para o IHRF, o estabelecimento do GGRF irá requerer grandes esforços da comunidade científica internacional no sentido de implantar os observatórios geodésicos fundamentais com boa distribuição espacial sobre o globo, em lugares estáveis, com tecnologia de ponta, com vistas a alcançar a precisão requerida para o estabelecimento dos EOS.

\section{Contribuição dos Autores}

Ambos os autores participaram das etapas de conceptualização, redação, revisão e edição do trabalho.

\section{Conflitos de Interesse}

Os autores declaram que não há conflito de interesse.

\section{Referências}

ALENCAR, J. C. M. Datum Altimétrico Brasileiro. Cadernos de Geociências, IBGE, n. 5, 1990, p. 69-73.

ALTAMIMI, Z.; REBISCHUNG, P.; MÉTIVIER, L.; COLLILIEUX, X. ITRF2014: A new release of the International Terrestrial Reference Frame modeling nonlinear station motions. Journal of Geophysical Research: Solid Earth, v. 121, n. 8, p. 6109-6131, August 2016. DOI.: 10.1002/2016JB013098.

BRASSAROTE, G. O. N. Modelagem Funcional e Estocástica de Séries Temporais para a Atualização e Estimativa da Componente Altimétrica: Aplicação no Sistema Geodésico Brasileiro. 2020. Tese (Doutorado em Ciências Cartográficas) - Faculdade de Ciências e Tecnologia, Universidade Estadual Paulista, Presidente Prudente, 2020.

CARRIÓN, J. L. Vínculo do Datum Vertical Equatoriano ao International Height Reference System IHRS. 2017. 265 p. Tese (Doutorado em Ciências Geodésicas) - Departamento de Geomática, Universidade Federal do Paraná, Curitiba, 2017.

CASTAÑEDA, R. M. Ensaio para definição de parâmetros de transformação entre o SAD 69 e o NSWC 9Z2. 1986. 180 p. Dissertação (Mestrado em Geociências) - Departamento de Geomática, Universidade Federal do Paraná, Curitiba, 1986.

COSTA, S. M. A. Integração da Rede Geodésica Brasileira aos Sistemas de Referência Terrestres. 1999. 157 p. Tese (Doutorado em Geociências) - Departamento de Geomática, Universidade Federal do Paraná, Curitiba, 1999.

DE FREITAS, S. R. C.; MEDINA, A. S.; LIMA, S. R. S. Associated problems to link South American Vertical Networks and possible approaches to face them. In: DREWES, H.; DODSON, A. H.; FORTES, L. P. S.; SÁNCHEZ, L. and SANDOVAL, P. (Ed.). Vertical Reference Systems. IAG Symposia Series 124. 
Berlin: Springer-Verlag, 2002. p. 318-323. DOI.: 10.1007/978-3-662-04683-8_59.

DE FREITAS, S. R. C. SIRGAS-WGIII activities for unifying height systems in Latin America. Revista Cartográfica, n. 91, p. 75-91, Enero-Diciembre 2015.

DREWES H.; SÁNCHEZ L. Velocity model for SIRGAS 2017: VEMOS2017. Technische Universitaet Muenchen, Deutsches Geodaetisches Forschungsinstitut (DGFI-TUM), IGS RNAAC (SIRGAS). 2020. DOI.: 10.1594/PANGAEA.912350.

FERREIRA, V. G.; MONTECINO, H. D.; NDEHEDEHE, C. E.; DEL RIO, R. A.; CUEVAS, A.; DE FREITAS, S. R. C. Determining seasonal displacements of Earth's crust in South America using observations from space-borne geodetic sensors and surface-loading models. Earth, Planets and Space, v. 71, n. 84, August 2019. DOI.: 10.1186/s40623-019-1062-2.

FENOGLIO, L. Sea Surface Determination with Respect to European Vertical Datums. München, 1996. 118 p. Dissertationen, Reihe C, Heft Nr. 464. Deutsche Geodätische Kommission.

FISCHER, I. The Basic Framework of the South American Datum of 1969. In: XII PAN AMERICAN CONSULTATION ON CARTOGRAPHY. Panamá, 1973. 18 p.

GEMAEL, C. Introdução à Geodésia Física. Curitiba: Editora da UFPR, 1999. 304 p.

GLOBAL GEODETIC OBSERVING SYSTEM (GGOS). Global Geodetic Observing System. 2020. Disponível em: <http://ggos.org/en/about/ggos-infos/>. Acesso em: jul. 2020.

HECK, B.; RUMMEL, R. Strategies for Solving the Vertical Datum Problem Using Terrestrial and Satellite Geodetic Data. In: SÜNKEL, H.; BAKER, T. (Ed.). Sea Surface Topography and the Geoid. International Association of Geodesy Symposia 104. Edinburgo, Escócia. Berlim: Springer-Verlag, 1990. p. 116-128.

HECK, B. Problems in the Definition of Vertical Reference Frames. In: SANSÒ, F. (Ed.). V Hotine-Marussi Symposium on Mathematical Geodesy. Berlin, Heidelberg: Springer, 2004. p. 164-173.

HOFMANN-WELlENHOF, B.; MORITZ, H. Physical Geodesy. Austria: Springer-Verlag, 2005. 404 p.

INTERNATIONAL ASSOCIATION OF GEODESY (IAG). IAG Resolution (No. 1) for the definition and realization of an International Height Reference System (IHRS). 2015. Disponível em: <https://office.iag-aig.org/doc/5d7b8fd9d31dc.pdf>. Acesso em: jul. 2020.

INTERNATIONAL ASSOCIATION OF GEODESY (IAG). Description of the Global Geodetic Reference Frame. 2016. Disponível em: <https://iag.dgfi.tum.de/fileadmin/IAGdocs/GGRF_description_by_the_IAG_V2.pdf>. Acesso em: jul. 2020.

INSTITUTO BRASILEIRO DE GEOGRAFIA E ESTATÍSTICA (IBGE). Ajustamento da Rede Planimétrica do Sistema Geodésico Brasileiro. Rio de Janeiro, Julho de 1996. 95 p. Disponível em: < https://geoftp.ibge.gov.br/informacoes_sobre_posicionamento_geodesico/rede_planialtimetrica/relatorio/ rel_sad69.pdf >. Acesso em: jul. 2020.

INSTITUTO BRASILEIRO DE GEOGRAFIA E ESTATÍSTICA (IBGE). Especificações e Normas Gerais para Levantamentos Geodésicos. Coletânea das Normas Vigentes. Rio de Janeiro, 1998. 74 p.

INSTITUTO BRASILEIRO DE GEOGRAFIA E ESTATÍSTICA (IBGE). Proposta preliminar para a adoção de um referencial geocêntrico no Brasil. Documento preliminar - texto para discussão. Grupos de Trabalho I e II. Rio de Janeiro, Outubro de 2000. 30 p.

INSTITUTO BRASILEIRO DE GEOGRAFIA E ESTATÍSTICA (IBGE). Sistema de Referência Geocêntrico para a América do Sul - SIRGAS. Boletim Informativo n 7. Rio de Janeiro, dez. 2002. $111 \mathrm{p}$.

INTERNATIONAL EARTH ROTATION AND REFERENCE SYSTEMS SERVICE (IERS). IERS Technical Note No. 36. In: PETIT, G.; LUZUM, B. (Ed.). IERS Conventions (2010). 2010.

INTERNATIONAL EARTH ROTATION AND REFERENCE SYSTEMS SERVICE (IERS). The Earth Orientation Parameters. Disponível em: <https://www.iers.org/IERS/EN/Science/EarthRotation/EOP.html>. Acesso em: jul. 2020. 
IHDE, J.; SIDERIS, M. Action Plans 2011 - 2015 for the GGOS-Theme 1: Unified Global Height System. Global Geodetic Observing System - GGOS 2020. 2010.

INTERNATIONAL LASER RANGING SERVICE (ILRS). Terms of Reference, 2020. Disponível em: <https://ilrs.gsfc.nasa.gov/about/termsofref.html>. Acesso em: out. 2020.

LAMBECK, K. Geophysical Geodesy: the slow deformation of the Earth. Clarendon: Oxford University Press, 1988. 718p.

MONTECINO, H. D.; DE FREITAS, S. R. C.; BÁEZ, J. C.; FERREIRA, V. G. Effects on Chilean Vertical Reference Frame due to the Maule Earthquake co-seismic and post-seismic effects. Journal of Geodynamics, v. 112, p. 22-30, December 2017. DOI.: 10.1016/j.jog.2017.07.006.

OLIVEIRA, L. C. de. Realizações do Sistema Geodésico Brasileiro Associadas ao SAD 69 - Uma Proposta Metodológica de Transformação.1998. 197 p. Tese (Doutorado em Engenharia) - Escola Politécnica da Universidade de São Paulo, São Paulo, 1998.

PAN, M.; SJÖBERG, L. E. Unification of vertical datums by GPS and gravimetric geoid models with application to Fennoscandia. Journal of Geodesy, v. 72, n. 2, p. 64-70, February 1998. DOI.: 10.1007/s001900050149.

PLAG, H.-P.; BEUTLER, G.; GROSS, R.; HERRING, T. A.; RIZOS, C.; RUMMEL, R.; SAHAGIAN, D.; ZUMBERGE, J. Introduction. In: PLAG, H.-P.; PEARLMAN, M. (Ed.). Global Geodetic Observing System. Meeting the Requirements of a Global Society on a Changing Planet in 2020. Berlin Heidelberg: Springer-Verlag, 2009. p. 1-14.

SÁNCHEZ, L. Towards a vertical datum standardisation under the umbrella of Global Geodetic Observing System. Journal of Geodetic Science, v. 2, n. 4, p. 325-342, 2012. DOI.: 10.2478/v10156-012-0002-x.

SANTACRUZ JARAMILLO, A.; DE FREITAS, S. R. C.; LUZ, R. T. Physical connection between BVRF segments based on leveling associated with gravimetry. Bulletin of Geodetic Sciences, v. 25, n. 1, p. 116, 2019. DOI.: 10.1590/s1982-21702019000100006.

SEEBER, G. Satellite Geodesy: Foundations, Methods and Applications. $2^{\text {nd }}$ ed. Berlin, New York: De Gruyter, 2003. $589 \mathrm{p}$.

SMITH, J. R. Introduction to Geodesy: the history and concepts of modern geodesy. New York, Chichester, Weinheim, Brisbane, Singapore, Toronto: Wiley Interscience publication, 1996. 224 p.

TORGE, W; MÜLLER, J. Geodesy. $4^{\text {th }}$ ed. Germany: De Gruyter, 2012. 433 p.

UNITED NATIONS. United Nations General Assembly. 2015. Disponível em: <https://ggim.un.org/documents/A_RES_69_266_E.pdf>. Acesso em: jul. 2020.

VANÍČEK, P.; KRAKIWSKY, E. J. Geodesy: The Concepts. $2^{\text {nd }}$ ed. Amsterdam: North-Holland, 1986. 697 p.

\section{Biografias dos autores}

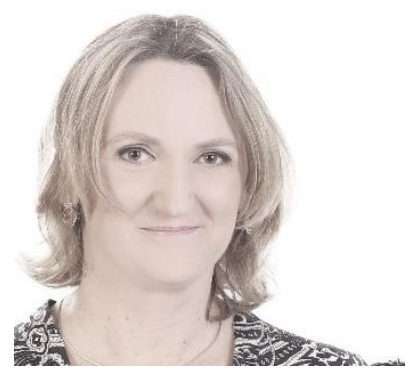

Regiane Dalazoana, nascida em 17/03/1975 em Curitiba-PR. Engenheira Cartógrafa formada pela Universidade Federal do Paraná em 1998. Mestre e Doutora em Ciências Geodésicas pelo Programa de Pós-Graduação em Ciências Geodésicas da UFPR. Em 2004, durante o doutorado, realizou estágio de curta duração no DGFI (Deutsches Geodätisches Forschungsinstitut) em Munique, Alemanha. Atualmente é professora do Departamento de Geomática da UFPR, ministrando aulas na graduação e pós-graduação. Coordena o Laboratório de Referenciais Geodésicos e Altimetria por Satélites (LARAS), atuando principalmente nos seguintes temas: sistema geodésico de referência, redes geodésicas de referência e altimetria por satélites. 


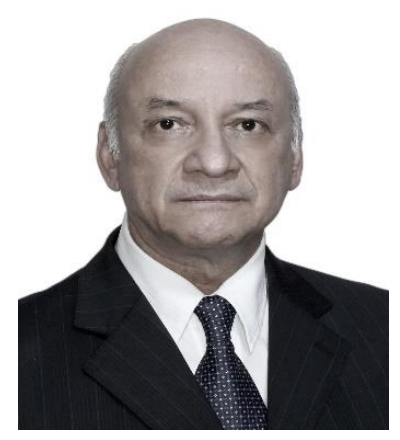

Sílvio de Freitas é docente desde 01/03/1971. Atualmente é Professor Colaborador do Programa de Pós-Graduação em Ciências Geodésicas da UFPR. Graduado em Física (UFPR - 1975), Mestre em Ciências Geodésicas (UFPR - 1980) e Doutor em Geofísica (IAG/USP - 1993) com estágio sanduiche de um ano no Observatório Real da Bélgica na área de Geodinâmica. Realizou atividades de pesquisa no DGFIem Munique e Universidade de Karlsruhe, Alemanha. Atua com ênfase em Sistemas Geodésicos de Referência, Geodésia Física e Geodinâmica envolvendo os temas: interação oceano-continente, gravimetria, marés, altimetria e gravimetria por satélites, INS e GPS/GNSS. devido crédito pela criação original. 